\title{
Judiciário e política regulatória: instituições e preferências sob a ótica dos custos de transação
}

\author{
RAFAEL SILVEIRA E SILVA \\ ÁLVARO P. S. COSTA JÚNIOR*
}

\begin{abstract}
$\sqrt{3}$
Judiciary and regulatory policy. Increasingly, judges and the courts appear as actors capable of affecting the trajectory of the government decisions, as strategic agents in the policy process. This paper presents an analytical model able to clearly and objectively measure the impact of judicial review in the design of policies in the sphere of economic regulation. Underlying the model is the concept of transaction costs, through which one can raise the levels of intervention of the judiciary in regulatory policy. In addition to the analytical model, the article demonstrates that the interaction between the heterogeneity of preferences in the courts and institutional mechanisms of the justice system is capable of generating greater coordination and cooperation than expected.
\end{abstract}

Keywords: Judiciary; regulatory policy; judicialization; transaction costs.

Jel Classification: K12; K23; K41; P46.

Cada vez mais os juízes e as cortes surgem como atores relevantes, capazes de afetar a trajetória das políticas públicas. Como bem apontou Taylor (2007), a dificuldade de elaborar estratégias analíticas capazes de traduzir, com clareza e objetividade, as repercussões da revisão judicial no desenho das políticas públicas ainda impõe importantes barreiras aos estudos dos tribunais na agenda de pesquisa contemporânea sobre as instituições políticas.

\footnotetext{
* Mestre e doutorando pelo Instituto de Ciência Política da UnB, consultor legislativo do Senado Federal. E-mail: rsilveirasilva@gmail.com. Diretor de Pesquisas do Instituto de Gestão, Economia e Políticas Públicas - IGEPP, Mestre em Ciência Política pela Universidade de Brasília — UNB. E-mail: alvarojr@igepp.com.br. Versão preliminar deste artigo foi apresentada no $6^{\circ}$ Encontro da Associação Brasileira de Ciência Política, realizado em 2008, em Campinas, São Paulo. Os autores agradecem os comentários feitos, à ocasião, pelo professor Matthew M. Taylor, e aos pareceristas anônimos da Revista de Economia Política. Submetido: 30/12/2008; Aprovado: 22/3/2010.
} 
Este artigo apresenta um modelo capaz de traduzir o impacto político da revisão judicial nas políticas públicas. Subjacente ao modelo está o conceito de custo de transação político, pelo qual é possível interpretar o processo de formulação de ações governamentais, examinando-se os vários mecanismos a ele subjacentes. Entendemos que o modelo proposto facilita a compreensão de que as instituições judiciais e as preferências dos magistrados constituem, de forma articulada, fatores determinantes na aplicação de políticas públicas.

Para materializarmos esse tipo de análise, trataremos da controvérsia judicial resultante da revisão das tarifas dos serviços de telefonia fixa ocorrida em 2003. Esse caso foi emblemático, pois, em um primeiro momento, houve alteração substancial de aspectos da política regulatória, por meio da aplicação de índice de reajuste diverso ao estabelecido pela agência reguladora. As centenas de decisões judiciais proferidas no país reforçam a percepção cada vez maior de que os juízes estão assumindo uma postura ativista com relação às políticas de governo, não hesitando, muitas vezes, em substituir o policymaker.

\section{ATIVISMO DO JUDICIÁRIO NO BRASIL}

A recente experiência brasileira ${ }^{1}$ indica um significativo grau de ativismo de juízes, lançando luz sobre o impacto dos tribunais no ciclo de políticas públicas ${ }^{2}$, seja no momento da implementação ou mesmo no âmbito da formulação, indicando uma atuação que vem superando o controle da legalidade e da constitucionalidade das leis. Nesses termos, o Judiciário passa a ser uma arena decisória com relevante capacidade de alterar o conteúdo das políticas públicas.

Essa tendência é explicada por Taylor (2007) pelo fato de que uma quantidade crescente de grupos organizados procura o local institucional mais favorável para contestar as políticas públicas (venue-seeking), seja esse local o Judiciário, as agências reguladoras ou as burocracias específicas. Segundo o autor, o conceito de venue-seeking sugere que os atores políticos procuram as instâncias institucionais que mais lhes convêm. Quanto mais a política tiver um caráter contencioso, mais expressivo esse fenômeno se mostra. No caso brasileiro, as políticas regulatórias apresentam relação forte com esse tipo de comportamento.

Não existe unanimidade em torno da judicialização das políticas públicas. Há correntes que desconfiam desse crescente ativismo judicial, afirmando que as decisões das cortes e dos juízes não são suficientemente voltadas para garantir os contratos e os direitos de propriedade, para moderar a instabilidade das regras e

\footnotetext{
${ }^{1}$ Podemos citar como episódios marcantes as ações e liminares que marcaram o processo de privatização da Companhia Vale do Rio Doce, do sistema Telebrás e do Banespa, bem como casos recorrentes de decisões judiciais obrigando o pagamento de medicamentos e tratamentos não contemplados pelo Sistema Único de Saúde.

${ }^{2}$ Para os fins deste artigo, entende-se por ciclo de política o conjunto formado pelos processos de formulação, implementação, monitoramento e avaliação de determinada política pública.
} 
para impedir expropriações contratuais por parte de agente econômicos e políticos (Levy e Spiller, 1996; Noll, 1999). Além disso, haveria uma tendência de comportamento em favor do gozo de direitos sociais, muitos dos quais assumindo condição de verdadeiras políticas públicas adotadas pelo governo em benefício da população (Pinheiro, 2000).

Arida, Bacha e Lara-Resende (2004) argumentam que a configuração das instituições políticas e judiciais do país afeta de maneira negativa o lado da oferta do crédito, quer em razão dos gargalos do sistema judicial que provoca morosidade na entrega da prestação jurisdicional, quer em razão da existência do que os autores identificaram como um viés anticredor dos tomadores de decisão no âmbito do sistema político e judicial. Segundo os autores, a descentralização do processo decisório e o alto grau de independência dos juízes faz do Judiciário, a contrario sensu, uma fonte de incertezas regulatórias.

Entendemos que essas visões pessimistas acerca da atuação exercida pelo Judiciário não explicam totalmente as decisões desse poder no ciclo das políticas públicas brasileiras, principalmente porque os autores negligenciam a heterogeneidade das preferências nos tribunais e o papel dos mecanismos institucionais capazes de gerar maior coordenação e cooperação do que o previsto.

Tais visões ignoram o fato de que, ao discordar de uma política, muitas vezes o juiz pode contribuir, legitimamente, para seu aprimoramento, seja ampliando o espaço de discussão, interpretando direitos, observando os limites discricionários do Executivo ou mesmo interpretando de um modo específico e proativo a Constituição, expandindo o seu sentido e alcance.

Por isso torna-se relevante observar as preferências dos magistrados e o arcabouço institucional sobre o qual atuam necessariamente devem interagir, mesmo porque as decisões judiciais quase sempre não se esgotam na primeira instância.

\section{CUSTOS DE TRANSAÇÃO E POLÍTICA REGULATÓRIA}

De acordo com North (1990), os agentes não são capazes de deter todas as informações de que necessitam, nem de processá-las. Ademais, os mercados são imperfeitos, de modo que as informações são conhecidas de forma assimétrica, o que permite desigualdades de poder perante um ato de troca. Partindo desse pressuposto, os agentes buscam formas de obter as informações necessárias para fazer a melhor escolha possível e, também, para assegurar que os contratos estabelecidos para cada ato de troca sejam cumpridos. As informações e a segurança no cumprimento dos termos de troca só podem ser obtidas mediante custos: os custos de transação.

Estes incorporam os custos de mensuração, de avaliação do produto a ser transacionado e os custos que assegurem os direitos de propriedade e o cumprimento das normas vigentes, sejam formais ou informais. A existência de custos de transação justifica o surgimento de instituições econômicas, sociais e políticas que têm condições de reduzir tais custos (Toyoshima, 1999). 
Os custos de transação oferecem uma estrutura conceitual para analisar uma grande quantidade de problemas relativos a mercados, mas também a organizações e à política. Um dos principais pontos de análise dessa perspectiva está nas estruturas de governança, uma vez que estas podem influenciar a magnitude e a forma que os custos terão em uma dada interação - diferentes estruturas implicam diferentes custos.

Exemplificando, no campo das relações do mercado provedor de serviços públicos, existe um embate entre os provedores de serviços e os consumidores, determinando a mediação do Estado. A política vinculada à regulação econômica se justifica para assegurar a concorrência e pela existência de falhas de mercado, para garantir que a relação entre produtores e consumidores de determinado bem ou serviço seja eficiente e justa, adequando quantidade, qualidade e preço. Assim, a política regulatória é elaborada para atenuar ou eliminar os custos de transação, diminuindo o nível de tensão entre as partes.

No processo de implementação de uma política, o policymaker enfrenta limitações informacionais e barreiras advindas da interação de todos os agentes que, de fato ou potencialmente, estão a ela vinculados. Desse modo, políticas públicas, em tese associadas com a diminuição de custos de transação de ordem econômica, também se deparam, no momento da aplicação, com custos de natureza específica: os custos de transação políticos.

Os custos transacionais políticos estão relacionados a qualquer aspecto que dificulte a especificação, o monitoramento e a capacidade de aplicação de uma transação no âmbito político ou de uma política pública. Os custos transacionais políticos influem de maneira decisiva no poder de decisão sobre os parâmetros que serão determinados aos dispositivos normativos, sejam leis ou regulamentações (Silva, 2007).

A concepção de North é importante, especialmente quando convencionamos que as políticas públicas podem ser entendidas como acordos (North, 2005, p. 53), construídos pelo compromisso firmado entre os agentes públicos e a sociedade para a solução de problemas. Quanto mais difícil e complexo for dimensionar e aplicar os termos desse acordo, maior será o custo de transação político.

As políticas estatais dependem de decisões que permeiam os Poderes da União. Vencida a etapa de elaboração, negociada entre o Executivo e o Legislativo, ao ser posta em prática, cada vez mais frequentemente o Judiciário tem sido chamado a se pronunciar. Esta etapa adicional pode gerar custos de transação políticos, implicando adiamento e possibilidade de mudanças na política. Do ponto de vista de Bacha, Arida e Lara-Rezende (2004), esses custos seriam tão altos e desfavoráveis ao mercado que tornam o Judiciário ator de veto e que impõe fragilidade aos investimentos.

Entendemos que os custos de transação vinculados às ações do Judiciário estão associados à heterogeneidade das preferências nos tribunais e o papel dos mecanismos institucionais próprios do sistema de justiça. Tais custos podem ser nocivos, ou não, dependendo do grau e do modo de interferência na política regulatória, bem como de suas características. Afinal, não se pode negar o fato de que o formu- 
lador da política não é um ator neutro ou totalmente isento do processo. Portanto, é preciso enfatizar que nem sempre a postura contrária do juiz a uma parte favorecida pela política regulatória seja um fato negativo. A interpretação do que é a política pública pode variar de juiz para juiz, que, mesmo discordando do regulador, pode, legítima e acertadamente, aprimorar a política pública.

Em outras palavras, o Poder Judiciário, ao ser provocado para assegurar direitos e deveres, pode colaborar ativamente para o aprimoramento da política pública, mesmo se constituindo fonte geradora de custos de transação política.

Tal afirmação pode a princípio ser forte, atribuída muitas vezes à conotação negativa que muitas vezes se faz do termo "custo". Na nossa perspectiva, custos de transação entre os atores políticos são os sacrifícios com os quais uma organização, uma pessoa ou um governo têm de arcar a fim de atingir seus objetivos. Trata-se, pois, de um custo necessário para dirimir qualquer dúvida jurídica acerca do posicionamento do governo perante as relações entre atores sociais, fazendo do Judiciário um depositário da fé pública nas regras do jogo. Naturalmente, a ideia de controle e vigilância recíprocos de um poder sobre o outro relativamente ao cumprimento dos deveres constitucionais de cada um possibilita a aplicação de políticas públicas mais transparentes, responsivas e observadoras do equilíbrio entre todas as partes envolvidas.

Quando acionado pela parte não favorecida pela política regulatória, o sistema judicial será fonte de custos de transação para quem executa a política e para quem ela havia beneficiado. Para avaliar essa questão, considera-se "intervenção" a ação do Judiciário no sentido de interpor etapas adicionais ao ciclo da política pública. Quanto maior o grau de intervenção do Judiciário, maior será o nível atribuído ao custo de transação.

Com base nesse referencial, acreditamos ser possível observar os custos de transação políticos gerados ao longo do processo decisório do Judiciário quando este interfere direta ou indiretamente na implementação de uma política pública, buscando vínculos nos fatores institucionais do sistema de justiça e as preferências dos seus membros. É importante ressaltar que nosso objetivo não é avaliar a política e as possíveis modificações aplicadas pelos juízes e pelas cortes, mas medir o custo de transação interposto por esses atores ao objetivo do administrador público, que é a aplicação de uma política. Para posterior adaptação ao estudo de caso, o modelo será adaptado para estudar os custos de transação aplicados a uma política pública regulatória.

\section{MODELO DE INTERAÇÃO ENTRE O JUDICIÁRIO E POLÍTICAS REGULATÓRIAS}

Com base na análise das decisões judiciais podemos mensurar o grau de incidência dos custos de transação nelas envolvidos. Propõe-se, então, a criação de um modelo analítico (heurístico) que leve em consideração as características do arcabouço institucional do sistema de justiça e as preferências dos magistrados. 
O modelo contempla dois índices de custos transacionais referentes à implementação das políticas regulatórias. O primeiro índice, vinculado ao arcabouço institucional do sistema de justiça, considera os custos de transação subjacentes aos contextos decisórios no âmbito da justiça: a primeira instância (justiça de primeiro grau), a segunda instância (Tribunais Regionais Federais e/ou Estaduais) e a última instância (Supremo Tribunal Federal — STF ou Superior Tribunal de Justiça - STJ). Quanto maior a descentralização do processo de tomada de decisões, maior chance de revisão da política pública. O segundo índice será construído a partir das preferências dos magistrados e das cortes em relação ao conteúdo e aplicação da política. Quanto menor a convicção do juiz quanto à predominância das regras aplicadas, maior o custo de enforcement das decisões de política.

Nossa unidade de análise será cada processo movido em contestação a uma determinada política. Cada índice terá em sua composição um ou mais indicadores, que são fatores ou aspectos que ajudam a explicar a formação do custo de transação. Tais indicadores possuem diferentes níveis, que serão ponderados por pesos. Desse modo, verifica-se em que nível se encaixa uma decisão judicial. Quanto maior o peso correspondente, maior será a contribuição no custo de transação ${ }^{3}$.

$\mathrm{Na}$ análise dos processos, será observado o nível de contribuição de cada indicador para a formação do índice de custos de transação. O escore determinado a cada indicador terá uma escala que variará entre " 0 " (menor incidência de custos de transação) a "1" (maior incidência).

\section{Custo de transação associado às instituições do Judiciário $\left(\mathrm{CT}_{1}\right)$}

O primeiro índice, que representa o custo de transação associado ao desenho institucional do sistema de justiça, denominaremos $\mathrm{CT}_{1}$. Para construí-lo tomaremos como base os seguintes indicadores: (i) quantidade de pontos institucionais de veto na instância decisória no âmbito do sistema de justiça; (ii) existência de mecanismos institucionais de reforço dos precedentes; (iii) existência de mecanismos institucionais de controle das instâncias inferiores; e (iv) existência de recursos institucionais à disposição do controlador de agenda no tribunal (agenda-setter).

Quadro 1: Custos de transação associados ao desenho do Judiciário $\left(C T_{1}\right)^{4}$

\begin{tabular}{|l|c|c|}
\hline \multicolumn{1}{|c|}{ Indicadores e Níveis } & $\begin{array}{c}\text { Peso } \\
\text { (A) }\end{array}$ & $\begin{array}{c}\text { Escore } \\
(1 / \mathrm{N}-1) .(\mathrm{A})^{*}\end{array}$ \\
\hline 1. Instâncias decisórias & & \\
1.1 Ministros do STF & 0 & 0 \\
1.2 Ministros do STJ & 1 & 0,25 \\
\hline 1.3 Desembargadores das cortes Estaduais ou Federais & 2 & 0,50 \\
\hline
\end{tabular}

\footnotetext{
${ }^{3}$ Para maiores detalhes ver o Anexo "Cálculo dos escores para os níveis de custo de transação".

${ }^{4}$ Para compreender os valores dos escores, ver nos Anexos a nota metodológica "Cálculo dos escores para os níveis de custo de transação".
} 


\begin{tabular}{|l|c|c|}
\hline \multicolumn{1}{|c|}{ Indicadores e Níveis } & $\begin{array}{c}\text { Peso } \\
\text { (A) }\end{array}$ & $\begin{array}{c}\text { Escore } \\
(1 / \mathrm{N}-1) \text {.(A)* }\end{array}$ \\
\hline 1.4 Juízes Estaduais e Federais & 3 & 0,75 \\
1.5 Juízes dos Juizados Especiais & 4 & 1 \\
\hline $\begin{array}{l}\text { 2. Reforço dos precedentes } \\
\text { 2.1 Súmula Vinculante e Repercussão Geral }\end{array}$ & 0 & 0 \\
2.2 Súmula Impeditiva de Recursos & 1 & 0,33 \\
2.3 Outros, exceto as súmulas acima indicadas & 2 & 0,66 \\
2.4 Não há & 3 & 1 \\
\hline 3. Controle das instâncias superiores sobre as inferiores & & 0 \\
3.1 Mecanismo de "dupla suspensão" de decisões pela cúpula \\
3.2 Mecanismo de suspensão de decisões via recursal especial \\
$\quad$ ou extraordinária & 0 & 1 \\
3.3 Mecanismo de suspensão de decisões via recursal ordinária & 2 & 0,5 \\
\hline 4. Recursos disponíveis ao controlador da agenda (agenda setter) & & 1 \\
4.1 Sim, estão disponíveis & 0 & 0 \\
4.2 Não estão disponíveis (ou não se aplica) & 1 & 1 \\
\hline
\end{tabular}

* $N$ é a quantidade de níveis existentes para cada indicador e Escore $\varepsilon[0 ; 1]$

O primeiro indicador relaciona-se à quantidade de potenciais tomadores de decisão (policymakers). Quanto mais numerosos eles forem, maior será a dispersão das fontes de poder e mais elevada será a probabilidade de que uma decisão judicial altere o curso da implementação da política. Quanto maior a descentralização do processo de tomada de decisões, maior a probabilidade de alteração do desenho da política pública. Em outras palavras, quanto menor a instância de julgamento, mais etapas de apelação haverá, implicando maior nível de custos de transação.

$\mathrm{O}$ outro indicador refere-se à existência de mecanismos institucionais de reforço dos precedentes. A preocupação está em saber se o contexto decisório no qual está sendo dado o encaminhamento da revisão judicial da política regulatória contempla regras de efeito vinculante a decisões reiteradamente proferidas. Quanto mais forte for o mecanismo de reforço de precedentes, mais rápido será o processo decisório judicial, reduzindo, assim, os custos de transação. Os melhores exemplos de que dispomos é o das súmulas vinculantes e o instrumento da repercussão geral, somente regulamentadas no final do ano de $2006^{5}$.

Além das súmulas, existem outros mecanismos também destinados ao reforço

\footnotetext{
${ }^{5}$ Prevista no art. 103-A da Constituição, a súmula vinculante representa o entendimento do STF sobre determinada matéria constitucional e terá efeito vinculante em relação aos demais órgãos do poder Judiciário e à administração pública direta e indireta, nas esferas federal, estadual e municipal. O objetivo é garantir a segurança jurídica e evitar a multiplicação de processos sobre questão idêntica. O instrumento da "repercussão geral" é uma espécie de "filtro recursal". Previsto do $\$ 3^{\circ}$ do art. 102 da Constituição, possibilita ao STF não conhecer os recursos extraordinários quando a questão constitucional neles versada não for relevante do ponto de vista econômico, político, social ou jurídico e a decisão não ultrapassar os interesses subjetivos da causa.
} 
dos precedentes. Costa Jr. (2007) cita, por exemplo, a Súmula Impeditiva de Recursos (Código de Processo Civil - CPC, art. 518), que consiste na inadmissão de recursos à instância superior caso já existam súmulas e jurisprudências dominantes do STF e STJ contrárias aos recursos. Quando tais situações ocorrerem, o juiz recebedor do recurso poderá decidir a questão liminarmente, isto é, sem ouvir a parte contrária ou remeter à instância superior tais recursos. Outra regra é a do trancamento de quaisquer recursos manifestamente inadmissíveis, improcedentes, prejudicados ou contrários à súmula do respectivo tribunal ou do tribunal superior (CPC, art. 557).

$\mathrm{O}$ terceiro indicador diz respeito à utilização de regras que permitam às cortes superiores suspenderem liminares de instâncias inferiores, exercendo um controle direto sobre a tomada de decisões ${ }^{6}$. No caso, o recurso da suspensão é remetido diretamente ao Presidente do Tribunal para conhecer e julgar o pedido de cassação de decisões das instâncias inferiores. O único requisito legal para o deferimento da medida suspensiva é o manifesto interesse público ou de flagrante ilegitimidade, no sentido de evitar grave lesão à ordem, à saúde, à segurança e à economia pública. Ainda existe o mecanismo conhecido por "dupla suspensão" de liminares, que autoriza a pessoa de direito público interessada (a União, a ANATEL, o INSS, entre outras) a recorrer ao STJ ou ao STF numa nova tentativa de suspender os efeitos de liminares concedidas, caso a suspensão na instância imediatamente inferior tenha sido negada.

O último indicador é uma medida relativa ao uso de prerrogativas institucionais à disposição do presidente da corte, que é o controlador da agenda, tais como o Agravo Regimental ${ }^{7}$. A lógica é a mesma dos demais indicadores. Quanto maior a possibilidade de centralização da tomada de decisão, menores os custos de transação.

$\mathrm{O} \mathrm{CT}_{1}$ é obtido da seguinte forma:

$$
C T_{1}=\sum_{i=1}^{4} \alpha_{i}
$$

onde i representa cada processo, tal que

$\alpha \mathrm{i} \epsilon[0 ; 1]$ representa o escore recebido por cada indicador; e $0 \leq \mathrm{CT} 1 \leq 4$.

Assim, esse índice variará de 0 a 4 , sendo 4 a situação que reflete a maior incidência de custos de transação sobre a implementação de uma política pública, ou seja, aquela em que houver o maior número possível de pontos institucionais de

\footnotetext{
${ }^{6}$ O Pedido de Suspensão de medida liminar é formulado diretamente ao Presidente do Tribunal para o qual será remetido o recurso de apelação ou o agravo de instrumento. Assim, cabe ao Presidente do Tribunal de Justiça, ou ao Presidente do TRF conhecer e julgar o Pedido de Suspensão de liminar ou sentença dos juízes de $1^{a}$ instância (suspensão via ordinária); ao Presidente do STJ conhecer e julgar o pedido de suspensão de liminar ou sentença concedida por Desembargadores Federais ou Estaduais, quando a matéria versar sobre interpretação e aplicação de norma Federal e ao Presidente do STF apreciar e decidir o Pedido de Suspensão de Liminar ou Sentença quando for Constitucional (suspensão recursal via especial e extraordinária, respectivamente).

${ }^{7}$ Agravo regimental ou agravo interno é um recurso judicial existente nos tribunais com o intuito de provocar a revisão de suas próprias decisões. Está muitas vezes previsto apenas nos regimentos internos dos tribunais e não na própria lei processual.
} 
veto com a ausência absoluta de qualquer mecanismo de controle das cortes superiores sobre as inferiores ou qualquer mecanismo de reforço dos precedentes.

\section{Custo de transação associado às preferências dos magistrados $\left(\mathrm{CT}_{2}\right)$}

O outro índice, que chamaremos de $\mathrm{CT}_{2}$, identifica as preferências dos juízes e também parte do pressuposto de que estas podem ser expressas de forma direcional.

$\mathrm{OCT}_{2}$ nos ajudará a visualizar o nível de adesão às políticas regulatórias aplicadas pelo governo. O índice será construído a partir dos seguintes indicadores: (i) interferência do Judiciário na implementação das políticas regulatórias (ativismo); (ii) preferência manifestada a favor da parte beneficiada pela política regulatória; e (iii) preferência acerca do desenho da política regulatória vigente ${ }^{8}$.

A atribuição dos escores aos níveis que compõem cada índice segue o mesmo procedimento utilizado na composição do $\mathrm{CT}_{1}$. Os valores dos escores para cada indicador estão distribuídos conforme quadro a seguir:

Quadro 2: Custos de transação associados

às preferências dos magistrados $\left(\mathrm{CT}_{2}\right)$

\begin{tabular}{|c|c|c|}
\hline Indicadores e Níveis & $\begin{array}{l}\text { Peso } \\
\text { (A) }\end{array}$ & $\begin{array}{l}\text { Escore } \\
(1 / \mathrm{N}-1) \cdot(\mathrm{A})^{*}\end{array}$ \\
\hline \multicolumn{3}{|l|}{ 1. Postura em face da interferência do Judiciário nas políticas públicas } \\
\hline 1.1 O Judiciário não deve intervir nas políticas públicas; & 0 & 0 \\
\hline 1.2 O Judiciário deve intervir nas políticas públicas (ativismo); & 1 & 1 \\
\hline \multicolumn{3}{|l|}{$\begin{array}{l}\text { 2. A decisão favorece a parte mais beneficiada pela política regulatória } \\
\text { vigente? }\end{array}$} \\
\hline $2.1 \mathrm{Sim} ;$ & 0 & 0 \\
\hline 2.2 Não; & 1 & 1 \\
\hline \multicolumn{3}{|l|}{$\begin{array}{l}\text { 3. Relativamente (i) à estrutura tarifária, (ii) à definição dos direitos e } \\
\text { deveres nos contratos regulatórios e (iii) ao fortalecimento institucional } \\
\text { das agências reguladoras, o magistrado é favorável: }\end{array}$} \\
\hline 3.1 A todos os aspectos; & 0 & 0 \\
\hline 3.2 A dois dos aspectos; & 1 & 0,33 \\
\hline 3.3 A um dos aspectos; & 2 & 0,66 \\
\hline 3.4 A nenhum dos aspectos. & 3 & 1 \\
\hline
\end{tabular}

* $N$ é a quantidade de níveis existentes para cada indicador e Escore $\varepsilon[0 ; 1]$

O primeiro indicador busca medir o grau de ativismo dos juízes. Por definição, quanto mais à vontade estiver o juiz para substituir o policymaker, maior a incidência dos custos de transação de execução da política, tendo em vista a possibili-

\footnotetext{
${ }^{8}$ Optou-se por não incluir ponderações distintas entre os indicadores na formação do índice. Ver Oliveira Filho (2005) sobre a sistemática adotada na construção de um indicador de independência das agências reguladoras.
} 
dade de alteração ou de um novo condicionamento. Do contrário, observará a força vinculante das convenções firmadas entre as partes.

O segundo indicador reflete a inclinação do juiz em decidir contra ou a favor da parte beneficiada pela política regulatória. Decidindo-se a favor da parte prejudicada, pode existir a possibilidade de o magistrado modificar o formato da política, distribuindo de outra forma algo que já possuía uma configuração prévia. Por exemplo, na esfera da regulação dos serviços públicos, se uma política regulatória favorece o consumidor, o comportamento do juiz em favor das concessionárias eleva a incidência de custos de transação sobre a política, aumentando a probabilidade do seu redesenho, de modo a compensar possíveis desigualdades entre as partes instauradas no estágio inicial da formulação.

O terceiro indicador busca capturar o nível de adesão dos juízes ao conteúdo da política regulatória vigente. Para consolidar essa perspectiva no modelo, selecionamos três aspectos para a avaliação. O primeiro, a definição estrutura tarifária, que implica a fixação, o reajuste e a revisão das tarifas, definindo ao longo do tempo o equilíbrio entre a taxa de retorno das empresas e a capacidade de pagamento dos consumidores. Outra questão é a forma como estão definidos os direitos, os deveres e os incentivos de consumidores e concessionárias. O último aspecto refere-se ao posicionamento do magistrado frente à legitimidade e a credibilidade da agência reguladora na proposição, execução e fiscalização da política regulatória. Quanto maior a chancela do juiz a cada um dos aspectos da política regulatória, menores os custos de transação para por plenamente em execução a política regulatória.

$\mathrm{CT}_{2}$ é obtido da mesma forma que $\mathrm{CT}_{1}$ :

$$
C T_{2}=\sum_{i=1}^{3} \alpha_{i}
$$

onde i representa cada processo, tal que

ai $€[0 ; 1]$ representa o escore atribuído a cada indicador após a análise; e $0 \leq$ $\mathrm{CT} 2 \leq 3$.

$\mathrm{O} \mathrm{CT}_{2}$ variará de 0 a 3 , sendo 3 a situação que reflete a maior incidência de custos de transação, na qual os juízes estão predispostos à alteração do conteúdo das políticas públicas, movidos principalmente por entenderem válido os recursos movidos pelas partes menos beneficiadas pela política e com fortes restrições ao formato da política pública conduzida pelo governo?.

\section{ESTUDO DE CASO: EPISÓDIO DA MAJORAÇÃO TARIFÁRIA}

Para testarmos o modelo, vamos aplicá-lo ao caso das decisões judiciais referentes à homologação do reajuste das tarifas dos serviços de telefonia fixa, ocorrida em

\footnotetext{
${ }^{9}$ Ver no Anexo a nota metodológica "Cálculo do custo de transação associado às preferências dos magistrados".
} 
2003. Esse reajuste foi homologado pela Agência Nacional de Telecomunicações (ANATEL) com base na variação do Índice Geral de Preços - Disponibilidade Interna (IGP-DI), da Fundação Getulio Vargas, referente ao ano de 2002. Essa decisão acarretou um reajuste médio de aproximadamente $30,05 \%$ sobre as tarifas, provocando o ajuizamento de várias ações em todo o País, as quais questionavam, em linhas gerais, o impacto negativo do aumento sobre a renda dos consumidores.

\section{Julgamento dos recursos na $1^{\mathrm{a}}$ instância}

$\mathrm{Na}$ ocasião havia uma clara conjugação de preferências entre o setor regulado e a ANATEL na aplicação da política, vinculada ao cumprimento dos contratos e, no outro extremo, o interesse dos consumidores, interessados em índices de reajuste inferiores aos previstos no contrato. Entretanto, a questão não estava pacificada dentro do Poder Executivo. Houve um embate público entre o Ministro das Comunicações e o Presidente da ANATEL ${ }^{10}$. O Poder Executivo buscou um acordo com as empresas do setor e com a ANATEL, a fim de diluir o impacto do IGP-DI no índice de inflação do país, até mesmo porque o índice era referência para as demais revisões tarifárias dos serviços públicos, como energia elétrica e pedágio. Mesmo assim, o Presidente da ANATEL anunciou o reajuste das tarifas, publicado em 27/6/2003, limitando-se a afirmar que apenas estava cumprindo o que estava no contrato. Frustrado o canal informal de negociação estabelecido entre o Governo Federal e a ANATEL, ações foram iniciadas em todo o país, com incentivo explícito do próprio Poder Executivo ${ }^{11}$.

Os requerentes, incluindo o Ministério Público, as associações de defesa do consumidor, as Promotorias de Defesa do Consumidor de todo o país, entre outros, consideravam legítima a alteração das cláusulas dos contratos firmados entre as concessionárias e o Poder Público, com apoio, principalmente, no marco legal de defesa do consumidor.

$\mathrm{Na}$ defesa das concessionárias era central o paradigma da estabilidade dos contratos. Argumentava-se que as disposições relativas às regras de atualização monetária dos contratos pelo IGP-DI foram previstos no edital de privatizações, configurando uma baliza para o fluxo de investimentos no setor. A alteração das regras do jogo aumentaria a incerteza jurídica no país, prejudicando, assim, a atração de novos investimentos para o setor, especialmente o de telecomunicações,

\footnotetext{
${ }^{10}$ O Ministro das Comunicações era o Deputado Miro Teixeira (PDT-RJ) e o Presidente da ANATEL, Luiz Guilherme Schymura, indicado pelo governo de Fernando Henrique Cardoso.

${ }^{11}$ Matérias veiculadas na imprensa informavam que o Ministério das Comunicações mobilizou seu gabinete para fornecer apoio técnicos às contestações judiciais. Ver, por exemplo, revista IstoÉ, "Cuidado com o telefone”, 2/7/2003. Neste artigo não entraremos no mérito da posição do Presidente da República e do Ministro das Comunicações quanto à questão. Apesar de suas posições claramente favoráveis à reavaliação dos contratos, consideraremos o valor institucional da agência reguladora como o ponto de vista da política de Estado.
} 
marcado pela dificuldade de reversão dos investimentos realizados (sunk costs) ou de direcionamento para outro setor (asset specificity).

Em 2003, a Justiça Federal de $1^{\text {a }}$ Instância contava com 560 varas federais criadas, com 527 juízes federais titulares efetivamente em exercício e 472 substitutos. Os pontos de veto, contudo, se situavam não apenas no Judiciário Federal, mas também na Justiça Estadual, tendo em vista que muitas das ações eram movidas apenas contra as concessionárias dos serviços públicos de telefonia, sem a inclusão da ANATEL no polo passivo, denotando competência de julgamento para juízes estaduais posicionados nas diversas comarcas do país.

No que se refere à captura dos custos de transação da dimensão institucional $\left(\mathrm{CT}_{1}\right)$ associados à primeira instância e tendo como base a codificação definida pelo modelo, houve a combinação das seguintes características:

Quadro 3: $\mathrm{CT}_{1}$ associado à primeira instância de julgamento

\begin{tabular}{|l|l|c|}
\hline \multicolumn{1}{|c|}{ Indicador } & \multicolumn{1}{|c|}{ Comentário } & Escore \\
\hline $\begin{array}{l}\text { Pontos de veto institucional } \\
\text { na Justiça Federal e } \\
\text { Estadual }\end{array}$ & $\begin{array}{l}\text { A matéria poderia ser apreciada tanto na Justiça } \\
\text { Federal como na Estadual }\end{array}$ & 0,75 \\
\hline $\begin{array}{l}\text { Mecanismos institucionais } \\
\text { de reforço dos precedentes }\end{array}$ & $\begin{array}{l}\text { Na matéria que estava sendo julgada, não havia } \\
\text { qualquer mecanismo de reforço de precedentes. } \\
\text { Os juízes gozavam de extrema liberdade para } \\
\text { proferir as decisões. }\end{array}$ & 1,0 \\
\hline $\begin{array}{l}\text { Possibilidade de utilizar o } \\
\text { mecanismo da "dupla sus- } \\
\text { pensão" }\end{array}$ & $\begin{array}{l}\text { Havia possibilidade de controle das instâncias } \\
\text { superiores. O mecanismo institucional de "dupla } \\
\text { suspensão" das liminares contra o Poder Público } \\
\text { já vigorava. }\end{array}$ & 0 \\
\hline $\begin{array}{l}\text { Poderes institucionais do } \\
\text { agenda setter }\end{array}$ & $\begin{array}{l}\text { Na justiça de primeiro grau, não há órgão decisório } \\
\text { coletivo. }\end{array}$ & 1,0 \\
\hline & CT1 associado à primeira instância de julgamento & 2,75 \\
\hline
\end{tabular}

Quanto à análise da distribuição de preferências dos juízes do primeiro grau, foram acessadas 71 ações das instâncias ordinárias federais e estaduais remetidas ao Juízo do Distrito Federal por força de decisão do STJ. Considerando apenas as decisões em que houve apreciação do pedido de liminar consistente com alteração substancial do conteúdo da política regulatória, $89 \%$ dos juízes a concederam. O sistema de defesa do consumidor foi a razão de decidir predominante em $78 \%$ desses casos. Dos $11 \%$ não concedidos, a totalidade foi indeferida por conta da tese da prevalência do princípio da segurança jurídica e do respeito aos contratos.

Provocado por uma das firmas reguladas, o STJ, por maioria, decidiu pela reunião das ações em um único Juízo, determinando, também por unanimidade, a cassação dos efeitos de todas as liminares concedidas e as que viessem a ser conce- 
didas em outras ações. Em última análise, o STJ transformou os quase 600 pontos de veto institucionais em apenas um, além de ter acionado mecanismo institucional de efeito inverso por meio da cassação de todas as decisões proferidas pelas demais instâncias. O caso estava nas mãos apenas de um juiz ("juiz-chave”).

Frustrando a expectativa e o interesse das concessionárias, a preferência do "juiz-chave" 12 demonstrou-se mais acentuada que o "juiz-médio"13 da primeira instância, ou seja, foi visivelmente intervencionista. Ante a constatação de desequilíbrio econômico entre as partes, o "juiz-chave" mitigou o princípio liberal da autonomia da vontade e do poder vinculativo dos contratos em favor dos interesses difusos dos consumidores e dos usuários dos serviços públicos.

No momento, importa identificar as preferências dos juízes de cada um destes processos com base no modelo adotado de incidência de $\mathrm{CT}_{2}$.

Com base nesse índice $\mathrm{CT}_{2}$, verificamos no modelo unidimensional a preferência dos magistrados. Serviremo-nos dessa representação unidimensional, por meio do qual situaremos as preferências dos grupos de interesses, do regulador setorial e dos reguladores políticos no processo de revisão judicial dos itens da política regulatória em exame.

\begin{tabular}{|c|c|c|c|c|}
\hline \multirow[b]{3}{*}{ Indicador } & \multirow{2}{*}{\multicolumn{2}{|c|}{ "Juiz-médio" }} & \multirow{2}{*}{\multicolumn{2}{|c|}{ "Juiz-chave" }} \\
\hline & & & & \\
\hline & $\begin{array}{l}\text { Posicionamento } \\
\text { dos juízes }\end{array}$ & $\begin{array}{l}\text { Escore } \\
\text { médio* }\end{array}$ & Posicionamento & Escore \\
\hline $\begin{array}{l}\text { Sobre a inter- } \\
\text { ferência do } \\
\text { Judiciário nas } \\
\text { políticas públi- } \\
\text { cas (Ativismo) }\end{array}$ & $\begin{array}{l}\text { Observaram-se dois tipos de postu- } \\
\text { ras: (i) a possibilidade de alteração do } \\
\text { desenho da política foi um forte indi- } \\
\text { cativo para a concessão das liminares } \\
\text { (ii) os indeferimentos das liminares } \\
\text { foram amplamente identificados por } \\
\text { meio do princípio da inalterabilidade } \\
\text { dos contratos pelo Judiciário. }\end{array}$ & 0,74 & $\begin{array}{l}\text { Juiz concedeu } \\
\text { a liminar. }\end{array}$ & 1 \\
\hline $\begin{array}{l}\text { Preferência em } \\
\text { favor parte mais } \\
\text { beneficiada pela } \\
\text { política regula- } \\
\text { tória }\end{array}$ & $\begin{array}{l}\text { Na questão regulatória, a postura em } \\
\text { favor do consumidor foi considerada } \\
\text { como indicativo de preferência por } \\
\text { um viés social ou distributivo. Foi pre- } \\
\text { dominante nesta etapa. }\end{array}$ & 0,86 & $\begin{array}{l}\text { Viés em favor do } \\
\text { consumidor. }\end{array}$ & 1 \\
\hline
\end{tabular}

\footnotetext{
${ }^{12}$ No dia 11/9/2003, o Juiz Federal Substituto da $2^{\text {a }}$ Vara da Seção Judiciária do DF deferiu liminar assegurando a aplicação da variação do Índice de Preços ao Consumidor Amplo (IPCA), e não o IGP-DI. ${ }^{13}$ Termo "juiz-médio" é utilizado para definir a postura média encontrada (definida pelos indicadores) entre os juízes de primeira instância que julgaram os casos.
} 


\begin{tabular}{|c|c|c|c|c|}
\hline \multirow[b]{2}{*}{ Indicador } & \multicolumn{2}{|l|}{ "Juiz-médio" } & \multicolumn{2}{|c|}{ "Juiz-chave" } \\
\hline & $\begin{array}{l}\text { Posicionamento } \\
\text { dos juízes }\end{array}$ & $\begin{array}{l}\text { Escore } \\
\text { médio* }\end{array}$ & Posicionamento & Escore \\
\hline $\begin{array}{l}\text { Sobre o } \\
\text { desenho da } \\
\text { política } \\
\text { regulatória } \\
\text { vigente }\end{array}$ & $\begin{array}{l}\text { A não adesão ao status quo da } \\
\text { política tarifária foi determinante } \\
\text { para a concessão das liminares. } \\
\text { No polo inverso, a estabilidade dos } \\
\text { contratos regulatórios foi a razão } \\
\text { da não concessão. Também foram } \\
\text { observadas várias manifestações } \\
\text { em favor do esvaziamento do poder } \\
\text { institucional das agências reguladoras. }\end{array}$ & 0,55 & $\begin{array}{l}\text { Adotou o IPCA em } \\
\text { substituição ao } \\
\text { IGP-DI. Mitigou a } \\
\text { estabilidade dos } \\
\text { contratos. }\end{array}$ & 0,66 \\
\hline \multicolumn{2}{|c|}{ CT2 imposto pelo conjunto de juízes da $1^{a}$ instância } & 2,15 & $\begin{array}{l}\text { CT2 imposto } \\
\text { pelo Juiz-chave }\end{array}$ & 2,66 \\
\hline
\end{tabular}

* O Escore Médio nada mais é que a média encontrada, para cada indicador, dos escores relacionados ao conjunto de decisões proferidas.

O evento revela ser importante para empreender a análise do impacto do Judiciário no processo político, observando-se ao mesmo tempo a configuração institucional do sistema de justiça e a distribuição de preferências das cortes e dos juízes.

\section{Julgamento do recurso na $2^{\mathrm{a}}$ instância e na cúpula (STJ)}

O conflito regulatório chegou à corte intermediária, o Tribunal Regional Federal da $1^{a}$ Região, quando as concessionárias entraram com novo recurso por meio de suspensão de liminar. Entretanto, os juízes da corte regional apresentaram considerável restrição com relação ao aspecto formal à admissão das empresas concessionárias dos serviços de telefonia como partes legitimadas para propor a suspensão de liminar, uma vez que tal regime especial é destinado originariamente a Pessoas Jurídicas de Direito Público ${ }^{14}$. Além disso, o voto proferido pelo relator da matéria, e aprovado pela maioria da corte, limitou-se a registrar que não restaram demonstrados de forma firme pelas empresas os prejuízos sobre a ordem econômica alegados no pedido ${ }^{15}$.

Após o indeferimento da corte regional do pedido de cassação da decisão "pró-

\footnotetext{
${ }^{14} \mathrm{O}$ voto do Presidente (em exercício) do TRF da $1^{\text {a }}$ Região revela esse embaraço: “Assim, de plano, data venia, a legitimidade para requerer a suspensão seria do MPF (o qual, naturalmente, não o faria, posto que o autor a Ação Civil Pública) e da própria ANATEL (que, para ingressar nos autos, não necessita de chamamento). Todavia, como a jurisprudência, ainda que vacilante, tem admitido a legitimidade de sociedades de economia mista e de concessionárias de serviço público e, como dentre os requerentes encontram-se um uma dessas sociedades [...] e duas concessionárias de serviço público [...], em homenagem a esse entendimento jurisprudencial (v.g. Resp 50.284/SP, Rel. Min. Peçanha Martins, e SS $n^{\circ} 26$, Rel. Min. Nilson Naves), com a ressalva de meu entendimento pessoal, reconheço a legitimidade para o requerimento". (grifamos)

${ }^{15}$ Como não houve manifestação por parte dos Desembargadores Federais quanto à questão de fundo da liminar deferida, não foi possível medir a tendência de suas decisões quanto à adesão à política pública.
} 
-IPCA", restaria às partes contrariadas apenas esperar o julgamento do mérito da ação civil pública original. Entretanto, por meio do instrumento da "dupla suspensão" permitiu-se às concessionárias apresentaram novo pedido de suspensão de liminar, dirigido agora ao Presidente do STJ, tendo em vista a natureza infraconstitucional da matéria.

Ao subir ao STJ, nova configuração de custos pode ser verificada, conforme revela o Quadro 5, que resume as características institucionais do julgamento na segunda e na última instâncias e pelo qual verificam-se menores custos transacionais por conta da considerável redução dos atores com poder de veto. No caso, foram 27 Desembargadores-Federais como os tomadores de decisão na segunda instância e 11 Ministros no STF.

Entretanto, se em termos institucionais os custos diminuíram sobremaneira, não havia garantia de que os custos oriundos das preferências dos ministros também seriam colocados no mesmo sentido.

Quadro 5: $\mathrm{CT}_{1}$ associado à segunda instância e à cúpula (STJ) de julgamento

\begin{tabular}{|l|l|c|c|}
\hline \multicolumn{1}{|c|}{ Indicador } & \multicolumn{1}{c|}{ Descrição } & \multicolumn{2}{c|}{ Média dos Escores } \\
\cline { 3 - 4 } & \multicolumn{1}{c|}{$\begin{array}{c}2^{\text {a }} \\
\text { Instância }\end{array}$} & STJ \\
\hline Instâncias decisórias & $\begin{array}{l}\text { Desembargadores das cortes Estaduais ou } \\
\text { Federais e Ministros do STJ. }\end{array}$ & 0,5 & 0,25 \\
\hline $\begin{array}{l}\text { Outros mecanismos } \\
\text { institucionais de reforço } \\
\text { dos precedentes }\end{array}$ & $\begin{array}{l}\text { As ferramentas disponíveis estavam associa- } \\
\text { das às regras de trancamento de recursos ma- } \\
\text { nifestamente inadmissíveis quando em con- } \\
\text { fronto com jurisprudência do Tribunal Superior. }\end{array}$ & 0,66 & 0,66 \\
\hline $\begin{array}{l}\text { Mecanismos de controle } \\
\text { das instâncias superio- } \\
\text { res sobre as inferiores }\end{array}$ & $\begin{array}{l}\text { Possibilidade de acionar o instituto da "dupla } \\
\text { suspensão". }\end{array}$ & 0 & 0 \\
\hline $\begin{array}{l}\text { Poderes institucionais } \\
\text { para o agenda setter }\end{array}$ & $\begin{array}{l}\text { Há uma série de prerrogativas institucionais } \\
\text { para o controlador da agenda: suspensão da } \\
\text { liminar e trancamento de recursos. }\end{array}$ & 0 & 0 \\
\hline \multicolumn{1}{c}{ CT, associado } & 1,16 & 0,91 \\
\hline
\end{tabular}

É preciso ressaltar um importante episódio nesta fase do processo. O então Presidente do STJ, Ministro Nilson Naves, indeferiu o pedido, em 20/1/2004, com entendimento semelhante aos magistrados da corte regional: a de que a via da suspensão de liminar não era a mais adequada para a solução da controvérsia. Restou às empresas mais um último recurso, pelo menos naquela via excepcional da suspensão de liminar: o agravo regimental, contra a decisão individual do Presidente.

Nesse ínterim, ocorreu a mudança da Presidência, assumindo o Ministro Edson Vidigal. Esse fato alterou definitivamente a dinâmica do processo. Diante do agravo regimental apresentado pelas concessionárias, o novo Ministro-Presidente argumentou que, a despeito da natureza excepcional da medida de suspensão de liminar ou de sentença, não poderia a análise do pedido prescindir de um exercício mínimo de deliberação do mérito. 
Essa mudança de postura ocorrida no âmbito do STJ mostrou-se decisiva. Quando da interposição do recurso pelas concessionárias, o presidente do tribunal, como controlador da agenda e detentor do primeiro movimento do jogo decisório, optou por permitir o exame da questão de fundo, a despeito da natureza excepcional da medida de suspensão de liminar. Assim, cassou a liminar, ao argumentar que ela, ao admitir a quebra do equilíbrio dos contratos e desprezar os investimentos feitos pelas empresas, poderia afastar os investidores, aumentando o risco Brasil e prejudicando o usuário que se buscou proteger.

Ao restabelecer o IGP-DI, o presidente do STJ não se pautou apenas no paradigma da estabilidade dos contratos e nas consequências econômicas para o setor regulado, conquanto tais razões já demonstrem posição favorável do Ministro pelo desenho geral da política regulatória estabelecida pela Agência. Ele foi além, adentrando os meandros da conveniência e oportunidade, típico das políticas públicas, ao comparar a aplicação dos dois índices no ambiente regulado, deixando a entender que o citado índice melhor refletia a realidade do setor. Importante frisar que o Ministro-Presidente não deixou de se comportar, também, como ativista e implementador da política tarifária, mas em regime de cooperação com a política regulatória e, consequentemente, com as concessionárias.

O Quadro 6 indica as preferências da Presidência do STJ e do "Ministro-médio" 16 da Corte. A Corte Especial do STJ, composta de 21 magistrados, proferiu 15 votos, incluindo o voto do Ministro Relator.

Quadro 6: $\mathrm{CT}_{2}$ associado ao STJ

\begin{tabular}{|l|l|c|c|}
\hline \multirow{2}{*}{ Indicador } & \multicolumn{1}{|c|}{ Posicionamento dos magistrados } & \multicolumn{2}{c|}{ Escores } \\
\cline { 3 - 4 } Ativismo & $\begin{array}{l}\text { Ministro atuou como policymaker, no } \\
\text { sentido de reverter a situação e resgatar } \\
\text { a política regulatória original. Sua postura } \\
\text { foi o de preservação da política original. }\end{array}$ & 0 & 0,6 \\
\hline -médio”
\end{tabular}

Foi possível verificar, então, uma distribuição de preferências no âmbito do STJ voltada para a chancela de aspectos essenciais do desenho da política pública regulatória: (i) adesão ao princípio da regra do cumprimento dos contratos regu-

\footnotetext{
${ }^{16}$ Segue o mesmo padrão de uso do termo “juiz-médio".
} 
latórios; (ii) cooperação com o regime tarifário vigente; (iii) deferência à autonomia da agência reguladora setorial no exercício de sua função de implementação da política de regulação em conformidade com marco regulatório das telecomunicações; (iv) preocupação com os impactos econômicos das decisões judiciais principalmente sobre o ambiente de investimentos do setor regulado; $(v)$ mitigação do sistema de defesa do consumidor.

No campo das regras, a despeito do conjunto complexo de pontos de veto no âmbito do sistema de justiça, há várias alternativas de controle institucional da cúpula do Judiciário sobre as instâncias intermediárias e inferiores. Entretanto tal prerrogativa não foi uma garantia de que tal controle implicasse divergências entre as preferências das referidas instâncias. Como se observou, a situação apenas foi alterada pela postura (também) ativista do agenda setter, o Presidente do STJ, Ministro Edson Vidigal.

\section{CONSIDERAÇÕES FINAIS}

Este artigo empreendeu uma análise do impacto do Judiciário na política regulatória por meio de dois prismas complementares: a configuração institucional do sistema de justiça e a distribuição de preferências das cortes e dos juízes.

Nossa hipótese foi a de que as instituições judiciais e as preferências dos magistrados constituem, de forma articulada, fatores determinantes do formato e da implementação da política.

Partiu-se do pressuposto de que qualquer barreira que interfira na implementação de políticas públicas (desde atraso até alterações mais profundas) decorrentes de decisões judiciais não é desejável aos policymakers. Essas interferências podem ser traduzidas pelos custos de transação políticos. Por meio de um modelo de mensuração foi possível capturar a incidência desses custos, na forma de dois índices: um refletindo as características institucionais do sistema de justiça e outro as preferências dos magistrados.

Outro aspecto interessante é o de que, com a introdução de mecanismos institucionais de reforços dos precedentes e centralizando a tomada de decisões, as deliberações do Judiciário tendem a ser menos fragmentadas. Isso significa que o conjunto de preferências da cúpula torna-se cada vez mais importante.

Nesse sentido, seria importante também investigar se há um "diálogo" entre as preferências da cúpula e da base do sistema judicial. No estudo de caso, verificaram-se diferentes preferências entre a cúpula e a base do sistema de justiça no que tange à política regulatória do setor de telecomunicações. Isso foi determinante para a aplicação da política original formulada pelo órgão regulador. No entanto, é preciso saber se esse comportamento também é observado em outras políticas públicas, ou seja, são necessários mais estudos para entender como e por que ocorrem diferenças entre as preferências das instâncias inferiores e superiores da justiça.

De maneira complementar, julgamos necessário analisar como está a agenda de discussão sobre determinada política pública. Isso poderá influenciar a relação de preferências entre a cúpula e a base. 
A pesquisa não avaliou os méritos da política regulatória ou das decisões. Mesmo exercendo o poder de revisão da política, entendemos que o papel do Judiciário não de ser entendido, a priori, como um fator negativo, especialmente no âmbito da construção de uma política mais equilibrada. Em outras palavras, a geração de custos de transação, indesejável num primeiro momento ao formulador, pode ser importante como via de aprimoramento da política. $\mathrm{O}$ magistrado muitas vezes interpreta e, ao discordar do regulador, legitimamente pode complementar a política pública.

Por fim, visualizamos promissoras oportunidades de aplicação do modelo de custos de transação na análise do papel do Judiciário em outras políticas públicas, tendo em vista ser um instrumental analítico interessante para visualizar o grau de intervenção e de interação do Judiciário nas políticas públicas. Espera-se que o modelo contribua na elucidação da natureza das decisões do Judiciário no ciclo das políticas públicas e para consolidar uma agenda de pesquisa sobre as instituições políticas brasileiras em que os juízes e as cortes ocupem o seu devido lugar.

\section{REFERÊNCIAS BIBLIOGRÁFICAS}

ARIDA, Pérsio; BACHA, Edmar e RESENDE, André Lara. (2004), “Credit, interest, and jurisdictional uncertainty: Conjectures on the case of Brazil”. Disponível em: <http://www.econ.puc-rio.br/ PDF/seminario/2004/Paper\%20Edmar\%20Bacha.pdf>. Acesso em: 10 mar. 2008.

COSTA Jr., Álvaro Pereira S. (2007), Judiciário e Política Regulatória: um estudo de caso sobre o papel das cortes e dos juízes na regulação do setor de telecomunicações. Monografia (conclusão de curso). Dissertação de Mestrado. Universidade de Brasília, Instituto de Ciência Política.

NORTH, Douglass. (1990), Institutions, Institutional, Change and Economic Performance. Cambridge: Cambridge University Press.

. (2005), Understanding the Process of Economic Change. Princeton: Princeton University Press.

OLIVEIRA FILHO, G. J.; MACHADO, E. L. (2005), "Efeitos do desenho regulatório sobre a competitividade de setores de infraestrutura”, in Anita Kon. (org.). Indústria, Trabalho e Tecnologia:

Subsídios à Política Pública. Rio de Janeiro: EITT/PUCSP, v. 1, pp. 261-296.

PINHEIRO, Armando Castelar. (2000), Judiciário e Economia no Brasil, São Paulo: Editora Sumaré.

RODRIGUES, Sílvio. (2005), Direito Civil: Parte Geral - Vol. 1. São Paulo: Saraiva.

SILVA, R. S. e. (2007), O desenho institucional do estado sob uma perspectiva temporal: o caso da política regulatória dos fundos de pensão. Dissertação de Mestrado. Universidade de Brasília, Instituto de Ciência Política, $181 \mathrm{f}$.

TAYLOR, Matthew. M. (2005), "Citizens against the state: The riddle of high impact, low functionality courts in Brazil". Revista de Economia Política, v. 25, n. 4, pp. 418-438.

. (2007), "O judiciário e as políticas públicas no Brasil”, Dados, 2007, vol.50, nº 2, pp. 229-257.

TOYOSHIMA, S. H. (1999), "Instituições e desenvolvimento econômico - uma análise crítica das ideias de Douglass North”. Estudos Econômicos. São Paulo, 29, FIPE, pp. 95-112.

\section{ANEXOS - NOTAS METODOLÓGICAS}

\section{Cálculo dos escores para os níveis de custo de transação}

Parte-se do pressuposto de que o índice terá indicadores explicativos, os quais terão vários níveis conforme o grau de incidência de custo transacional. A incidên- 
cia de cada nível, deverá variar dentro do intervalo [0;1], ponderado pelo peso. A convenção é que o peso reflete como o nível influencia o custo de transação comparativamente aos demais, sendo que quanto maior ele for, maior a incidência de custos de transação. O peso partirá do valor " 0 " até o valor $N-1$, onde $N$ é a quantidade de níveis definidos para cada indicador. Desse modo, o escore obtido para cada nível obedecerá à seguinte fórmula:

$$
\text { Escore }=\frac{1}{N-1} \times \text { Peso }
$$

O quadro a seguir demonstra um conjunto de elementos a serem observados na análise de uma decisão judicial à luz de um indicador $(\mathrm{X})$ previamente escolhido. Tal indicador possui $N$ níveis, classificados em ordem crescente com relação ao peso.

\begin{tabular}{|c|c|c|c|c|}
\hline \multirow[b]{3}{*}{ Indicador } & \multicolumn{4}{|c|}{ Custos de Transação - Indicadores, níveis e escores } \\
\hline & \multicolumn{3}{|c|}{ Etapa de análise da decisão judicial } & \multirow[b]{2}{*}{$\begin{array}{c}\text { Escore atribuído ao } \\
\text { Indicador após a análise }\end{array}$} \\
\hline & Níveis & Peso & Escore & \\
\hline \multirow{5}{*}{ Indicador X } & $X_{1}$ & 0 & 0 & \multirow{5}{*}{$1 / \mathrm{N}-1$} \\
\hline & $x_{2}$ & 1 & $1 / \mathrm{N}-1$ & \\
\hline & $x_{3}$ & 2 & $2 / N-1$ & \\
\hline & $\cdots$ & $\ldots$ & $\ldots$ & \\
\hline & $X_{N}$ & $\mathrm{~N}-1$ & 1 & \\
\hline
\end{tabular}

Realizando uma simulação de pesquisa, com relação ao Indicador "X", o nível $\mathrm{X}_{2}$ de custo transacional foi o que mais se encaixou com o perfil da decisão judicial. Conclui-se que o escore daquele indicador será $1 / \mathrm{N}-1$.

Realizado esse procedimento para todos os indicadores, o valor do índice de custo de transação (CT) será obtido da seguinte forma:

$$
C T=\sum_{i=1}^{n} \alpha_{i}
$$

Onde $n$ representa o número de indicadores selecionados para avaliar cada CT;

$i$ representa cada processo;

$\alpha_{\mathrm{i}} \varepsilon[0 ; 1]$ representa o escore atribuído a cada indicador após a análise; e $0 \leq$ $\mathrm{CT} \leq n$.

\section{Cálculo do custo de transação associado às preferências dos magistrados}

Para bem estabelecer as preferências dos magistrados ante política pública, pressupõe-se que os indicadores $\mathrm{CT}_{2}$ apresentam uma natureza ordinal e sequencial, 
abordando uma multiplicidade de alternativas possíveis para indicar os custos de transação subjacentes às preferências manifestadas em cada decisão judicial.

$\mathrm{O}$ cálculo de $\mathrm{CT}_{2}$ se assemelha ao de uma árvore de decisão (ver quadro ao lado), onde se apresenta um conjunto de decisões ao "nó inicial", no caso a postura pró ou contra o ativismo; dependendo dessa postura, o quadro de decisão ramifica-se para um dos "nós-filhos", ou seja, a preferência em favor ou não da parte mais beneficiada pela política. E, por último, as ramificações concernentes ao grau de adesão ao conteúdo da política regulatória. A ideia fundamental é a de que, para mapear as preferências, deve-se observar primeiramente a postura ativista, para depois verificar os demais aspectos que detalham o posicionamento do juiz manifestado em sua decisão.

\begin{tabular}{|c|c|c|c|c|}
\hline \multicolumn{5}{|c|}{ Quadro de decisão que define o valor do $\mathrm{CT}_{2}$ para cada juiz } \\
\hline & \multicolumn{3}{|c|}{ Indicadores e Escores } & \multirow{2}{*}{$\frac{\text { CT2 }}{\text { (D) }}$} \\
\hline & (A) & (B) & (C) & \\
\hline \multirow{9}{*}{$\begin{array}{c}\text { Aplicação dos Escores } \\
\text { a cada indicador }\end{array}$} & 0 & - & - & 0 \\
\hline & \multirow{8}{*}{1} & \multirow{4}{*}{0} & 0 & 1 \\
\hline & & & 0,33 & 1,33 \\
\hline & & & 0,66 & 1,66 \\
\hline & & & 1 & 2 \\
\hline & & \multirow{4}{*}{1} & 0 & 2 \\
\hline & & & 0,33 & 2,33 \\
\hline & & & 0,66 & 2,66 \\
\hline & & & 1 & 3 \\
\hline
\end{tabular}

Obs: os valores do quadro se baseiam no quadro de escores do estudo de caso.

Onde: (A) Ativismo;

(B) Preferência em favor da parte beneficiada pela política regulatória vigente;

(C) Preferência acerca do desenho da política;

(D) Cálculo proposto para o CT2. 